University for Business and Technology in Kosovo

UBT Knowledge Center

UBT International Conference

2013 UBT International Conference

Nov 2nd, 2:00 PM - 2:15 PM

\title{
Improving Energy Efficiency in Buildings in Republic of Kosovo
}

Ferhat Bejtullahu

University for Business and Technology, ferhatbej@gmail.com

Follow this and additional works at: https://knowledgecenter.ubt-uni.net/conference

Part of the Architecture Commons

\section{Recommended Citation}

Bejtullahu, Ferhat, "Improving Energy Efficiency in Buildings in Republic of Kosovo" (2013). UBT International Conference. 18.

https://knowledgecenter.ubt-uni.net/conference/2013/all-events/18

This Event is brought to you for free and open access by the Publication and Journals at UBT Knowledge Center. It has been accepted for inclusion in UBT International Conference by an authorized administrator of UBT Knowledge Center. For more information, please contact knowledge.center@ubt-uni.net. 


\title{
Improving Energy Efficiency in Buildings in Republic of Kosovo
}

\author{
Ferhat Bejtullahu \\ University for Business and Technology Republic of Kosovo \\ E-mail: ferhatbej@gmail.com
}

\begin{abstract}
Abs tract. The building sector is responsible for a substantial part of energy use in Europe and Kosovo. Buildings in Kosovo account for $40 \%$ of the total energy demand, but the building sector pays little or no attention to energy efficiency. The most relevant laws (Energy Efficiency law is in force since July 2011), administrative instructions, regulations and strategic documents in field of energy efficiency are almost completed but implementation and enforcement is still very weak.

Despite all this laws, new regulations and other measures that regulates technical requirements for thermal energy saving and thermal protection, application and management faces difficulties especially in planning and implementing energy efficiency in new buildings according to "ENERGY PERFORMANCE OF BUILDINGS DIRECTIVE 2010/31/EU" The paper will identify barriers and recommend appropriate methods and tools for improving energy efficiency in buildings through implementation of initiatives as efficiency labeling or certification that will raise buildings energy efficiency (EE) beyond minimum requirement and social, spatial and environmental measures for improving EE in buildings. The study concludes that most important factor for EE in buildings is reduction in energy demand in existing and new designed buildings. Best solution to achieve thes is creating a Building Model for Energy Evaluation
\end{abstract}

Key Words Kosovo, energy efficiency in buildings, improving

\section{Introduction}

Low awareness about economic and environmental EE measures is perhaps the most important form of investment inefficiency that could cause an absence of EE in buildings. There are two models of the lack of awareness concerning this issue. In the first model, consumers and firms may not have sufficient information about tools for improving EE buildings. Whilst in the second model, consumers and firms may be unaware of potential instruments and investments funds offered for improving EE. For example, homeowners may not know how poorly insulated their home is and may not be aware of opportunities of energy conservation. Similarly, designers may not know about a new type of software's that evaluates energy performance of buildings and calculates exact investment recovery cost.

An alternative model resembles Akerlof's (1970) [1] "lemons" model. Buyers know that different products, such as apartments, commercial buildings, or factory equipment, have different levels of energy efficiency, but these differences are costly to observe. Thus, they are not willing to pay more for goods that in fact insure more energy efficiency. For example, a renter evaluating a set of different apartments may be aware that there is a distribution of wall insulation quality and thus of resulting heating costs, but the renter will not be willing to pay more for a well-insulated heating costs, but the renter will not be willing to pay more for a well-insulated apartment without taking the time to inspect the insulation.

Regulations are perhaps the most effective policy instrument, as they mandate specific behaviors. However, as Scott (2001)[4] stresses, making the rules are not enough: monitoring adherence, and the use of sanctions if they are not followed, is also important element. Building regulations are the most important regulations that affect energy performance. They have primarily affected energy demand, as there are no requirements as to choose of heating system or energy carrier. 
The appliances that Davis (2010) [2] considers make up only one-quarter of residential energy use. Heating and cooling represent close to one-half, meaning that insulation is perhaps a more important investment that could be subject to the landlord-tenant agency problem.

\subsection{Research question}

The objective of this research is to identify the actual factors that have important impact in process of improving energy efficiency of buildings in Kosovo. The study focuses on the period of last decade, as this allows us to compare achievements s of contemporary events in region that are in process. By focusing on a period near in time, the study also allows the exploration of driving forces and barriers that may still be important. Attention and concern for climate change has increased in recent years, and is one of the factors that will be explored in this report as a possible driving force that makes pressure in all relevant factors in Kosovo for improving energy efficiency of buildings.

How the adequate methods and tools impact effectiveness of measures taken from all relevant factors in process of improving energy efficiency of buildings in Kosovo?

\subsection{Methodology}

Yin (2003) [5] stresses the importance of the research questions posed in deciding what methodology to use. When the research questions are how and why and the focus is on contemporary events, case studies may be the preferred methodology. The research questions of this paper require a methodology that can allow going in depth and studying energy use in buildings in relation to several factors. The objective is to analyze how the energy efficiency of buildings has developed after year 1999 and why it has developed in this way. A comparing methodology is used to identify development of energy performance of buildings and how changes have developed in Kosovo compared with states in region. However, it is not the best methodology when the aim is to explore the factors that have promoted or prevented improved energy efficiency ofKosovo buildings. This requires a methodology that allows us to study and understand complex phenomena. One central element in the case-study research design is data triangulation. Analyzing and comparing multiple sources of evidence, documents, interviews and observations and a mix of quantitative and qualitative data, will increase the validity and reliability of this research. According to Yin (2003) [5] a case study is especially appropriate when studying contextual conditions '...where the boundaries between phenomenon and context are not clearly evident...' (Yin 2003:13). This is also the case in the field of energy use in buildings in Kosovo. It is not possible to understand and explain the development of energy performance here without including this context as an important factor. Therefore, the case-study approach would appear to be an appropriate methodology for this study. However, the objective of this report is not to uncover causal relationship, but explore driving forces and barriers.

\subsection{Background and context}

The current level of energy efficiency in Kosovo is low, and it is entirely realistic to aim an increase of $20 \%$ in EE by 2020. The highest potential for EE improvement is in heating and electricity generation, where the current use efficiency is much under that determined by EU relevant directive and current technological standards in the EU on furnaces and small heating equipment.

Heating Strategy of the Republic of Kosovo 2011-2018

As signatory parties of the Energy Community Treaty (ECT), Kosovo is member of the En CT Task Force on Energy Efficiency (TF EE). Under guidance of TF EE, Ministry of Economic Development (MED) has developed the First National Energy Efficiency Action Plan (NEEAP) 2010-2018

NEEAP outlines the national targets on energy savings for the period 2010-2018. Earlier, in2007, Ministry of Energy and Mining (MEM) had developed the Kosovo three-year program for Energy Efficiency and Renewable Energy Sources. A number of projects of this program are under implementation. 
As in Table 1 presented the residential sector (buildings) with EE measures will be reduced in \% through years and by the end of year 2018 will participate with $3.6 \%$ less.

The objective of Kosovo is to achieve the set target of $9 \%$ energy saving by end of 2018 .

In its First National Energy Efficiency Action Plan (NEEAP) Kosovo 2010-2012 has adopted an intermediate target on energy saving.

NEEAP 2010-2018 sets EE long term targets for the period 2010-2018 and intermediate targets for 2010-2012. In determining the medium term targets, NEEAP has considered:

Lack of a Functional Energy Efficiency Agency and non-existence of Regional Energy Offices

Lack of a Fund for Energy Efficiency

Lack of a labeling system for Energy in Buildings

Lack of legal procedure mandating procurement of EE equipment for public entities

Lack of energy service companies

Delayed introduction of Labeling of Household Electric Appliances

Lack of complete data from accurate survey in the public sector regarding EE

Lack of decision to mandate public sector entities to undertake EE measures

Table 1 Participation of each Energy Sector with EE measures in \% through years

Source: Kosovo Energy Efficiency Plan 2010-2018, as approved by the Minister of Economic Development on 30 September 2011.

The Law on Energy Efficiency, No. 04/L-016, 22.07.2011, provides for the creation of the Energy Efficiency Agency. Establishment of the EE Agency and EE Fund will significantly contribute to the implementation of the NEEAP. This national target is allocated among sectors, including household, service, industry, transport, and agriculture. Household anticipated energy savings amount to $40 \%$ of the overall target to be saved during 2010-2012.

Kosovo's electricity tariffs are among the lowest in the region. Despite the low prices, the main issue in the sector is non-payment of energy bills. Similar to many other countries, district heating billing is based on the surface area of consumerdwellings, not metered consumption. In Prishtina, district heating serves about $20 \%$ of the population.

Kosovo haze partially adopted methodology for calculating energy performance of buildings. Figure1. Progress in implementation of EPBD (source: $16^{\text {th }}$ Energy Efficiency Task Force Meeting 10/11/2012 Vienna)

Source: Kosovo Energy Efficiency Agency - UPDATE ON KOSOVO's NEEAP

As reported at $16^{\text {th }}$ Energy Efficiency Task Force Meeting - 10/11/2012 in Vienna (Figure 1), Kosovo has partially adopted methodology for calculating energy performance of buildings but founds and building code are missing in process. Without founds and building code there is no continuity in procedure of adopting the standards necessary for the transposition of EU directive.

According to a World Bank study, the application of insulation materials and double glassed windows would bring a reduction of energy consumption for heating up to an estimated $35 \%$ in individual households. Kosovo wide, this would bring potential savings of heating to 500-600 GWh/year, around $12-14 \%$ of the current demand for heating.

With support from the donor community, including EC, GIZ, etc., GoK has implemented a number of energy efficiency measures in the public sector buildings and facilities like schools, hospitals and government building. Efficient lighting of buildings and streets and thermal insulation are among the key interventions. On the other hand, campaigns to raise consumer awareness, seeking to effectuate behavioral change in the residential sector, have been an important component of Kosovo energy efficiency plans.

\subsection{Barriers to energy efficiency in buildings}

Since EE is a cross-cutting is sue covering several policy areas, competencies and technologies, barriers exist in all principal elements of the institutional framework:

- Legal and regulatory frameworks are inadequate. A clear legal and regulatory framework is a prerequisite for $\mathrm{EE}$ investments. Basic $\mathrm{EE}$ legal framework exists but more progress needs to be made on the effective implementation of these frameworks. 
- Training and know-how are scarce. Despite good education systems, professional skills, knowledge, and expertise for technology distribution are scarce. Few architects, engineers, plumbers, and installers have the technical skills or knowledge to exploit energy savings potential. EE training is not included in most course curriculums. Also, without adequate systems and skills to reliably measure and verify energy savings EE measures will not be implemented on a enough large scale.

- Modern building codes and EE standards are not introduced and enforced. Such building codes must be introduced based on the European Building Directive, while appliance and other equipment standards should seek to meet EU standards as well. There is no sustained public information campaigns and national level control mechanism.

- One of the biggest barriers is the lack of EE funds. Many EE measures require investments with a payback period that is longer than many consumers find acceptable. EE fund s could provide subsidies for implementing EE investments, shortening the payback periods, and help provide access to below-market rate financing where necessary.

- Targeted information campaigns should be launched to raise awareness of the benefits of EE among investors and consumers. Consumers at all levels lack information to support EE behavior changes. For example, consumers often lack meters or heat cost allocators for district heating and billing information (all forms of energy) that would make them aware of their patterns of energy consumption. As a result, they have no idea how their consumption compares to that of their peers, how their consumption could be reduced, or what the benefits of reduced consumption are.

- Energy prices are low and cross-subsidized, while non-payment is a significant issue. Energy tariffs are low and cross-subsidized; this does not encourage energy efficiency investments, especially since the upfront cost of these investments is often quite high, because it does not help save consumers the full cost of energy avoided. In cases where consumers steal or otherwise don't pay for their energy consumption, strong incentives to undertake energy efficiency measures are lacking, except as a by-product of measures to enhance comfort in the buildings.

- Municipalities do not have appropriate structure to deal with EE measures in local level. Kosovo is delaying in establishing energy offices at the municipal level.

\section{Suggestions}

Complete legal and regulatory framework. Kosovo needs to continue completing the legal and regulatory framework in the area of energy efficiency as it is required under the Treaty establishing Energy Community (EnC). NEEAP provides details in this regard.

Develop institution to promote and monitor energy efficiency. Kosovo needs to functionalize the EE Agency as provided for in the Law on Energy Efficiency, No. 04/L-016, 22.07.2011. Clear role and responsibilities of this Agency are described also in the Ministry of Economic Development (MED) Regulation No.08/2011 "On Internal Organization of the Kosovo Agency for Energy Efficiency". Although the Law on Energy Efficiency does not provide for the creation of an Energy Efficiency Fund (EE Fund), the Kosovo Government needs to consult the donor community on this matter and decide appropriately. Annex 8 provides information on the legal and institutional arrangements in the area of energy efficiency in several EU and Balkan countries. On the other hand, it is appropriate to establish energy offices at the municipal level. All municipalities in Kosovo have departments dedicated to local development issues, including local infrastructures. Mandated responsibility for dealing with energy issues is missing in all of these departments. Law on Energy provides for the possibility of establishing of energy offices at the communal level. MED is prepared to provide training and other institutional development support so that these offices get up and running within a reasonable period of time. Several donors, such as European Commission Liais on Office (ECLO) and GIZ of Germany, have funded in the past energy training activities to communal officials. Annex 7 provides further reas ons on the need to establish communal energy offices. 


\subsection{Institutional framework}

Comprehensive and continued sustainable development and retention of qualified staff at all levels of government is a major challenge for the Kosovo energy sector institutions.

Further support to comprehensive development of the energy auditing institutions and infrastructure as well as to establishment of ESCO businesses should be part of the comprehensive institutional development in the area of energy efficiency in Kosovo. Respective actions anticipated in the NEEAP need to be undertaken.

Develop comprehensive energy data systems. Setting up energy data gathering and reporting systems consistent with those of EUROSTAT is an EU accession requirement. EU, through EnC, has engaged its relevant agencies in providing substantial technical support on setting up adequate energy statistic systems in the Western Balkans countries, so that useful energy efficiency indicators can be developed and monitoring of progress can be performed.

Incentives can help to overcome barriers to entering the market, for example, through special programs offering financial or technical support, or even temporary exemptions from standard administrative procedures. Incentives should be both of the demand-pull as well as the supply-push variety. Examples of important demand-pull incentives are introducing codes and standards, creating end-user awareness, and making concessionary financing available. Supply side measures involve actions such as providing tax incentives and financing for enterprises, easing import restrictions and duties on importing energy efficient equipment, training of auditors, architects and contractors, etc.

Remove barriers. As identified by the World Bank, major barriers include: (i) inadequate legal and regulatory frameworks, (ii) lack of incentives of all kinds, (iii) training and know-how are scarce, (iv) high investment costs for energy efficiency technology, (v) modern building codes and EE standards for appliances and equipment should be introduced and enforced, (vi) energy efficiency funds should be created, (vii) targeted information campaigns should be launched, and (viii) energy prices are low and cross-subsidized, while non-payment is a significant issue. A World Bank summary of barriers to enhancing energy efficiency in Western Balkans is presented in Annex 8.

Continue leading by example and enhancing public awareness on energy efficiency. Even without immediate improvements to data systems, tariff structures, and tariff levels, much can and should be done to increase EE. First, the public sector should continue leading the way by introducing EEdemandside measures in all its buildings, facilities, and rolling stock. Campaigns to raise consumer awareness and seek to effectuate behavioral change in the residential sectors (housing and transport) should continue. The efforts must be accompanied by firm commitment and actions to eliminate energy price distortions and gradually rais e energy prices to cost-recovery levels to enable rational consumer choices among energy efficiency investment options. Explore alternative models to funding of EE measures in public sector. Large energy-saving potential exists in the public sector, necessitating a substantial amount of public sector borrowing, if targets are to be met. The majority of funds currently available are targeted at private sector borrowing with a major emphasis on household and SMEs. This implies that funds and other mechanisms must be increasingly targeted at municipal services and public buildings. The borrowing capacity of the public sector at communal and national level is very limited and hence efforts will be required to find alternative models that allow funding to be made available to the public sector. Consider a state-level Public Building Rehabilitation Program. Many administration, health, and educational buildings are under state control and could be used to showcase EE improvements and provide the basis for a local service industry that performs energy audits and implements projects, perhaps supported by grants and IFI loans. This measure/program could be coupled very well along with development of public procurement policies that facilitate energy services. The Government, with donor assistance, should consider modifying its national public procurement policy to enable energy services contracting.

\subsection{Use of technology for evaluating $\mathrm{EE}$ of buildings}

The most important design decisions influencing a building's energy efficiency are made by the architect in the early phases of design. Introducing applications in evaluation of buildings energy efficiency is easiest way to set new standards in sustainable design. An application allows architects to perform reliable energy evaluation of their virtual buildings, relying on building geometric analys is and 
accurate hour-by-hour weather data of the project location. This process requires relatively few physical material properties that can be provided with simple and straightforward user input. A reliable, certified calculation engine performs dynamic building energy evaluation and provides information on physical performance of the project's applied constructions, yearly energy consumption, carbon footprint and monthly energy balance. This simple yet effective workflow makes energy evaluation just as easy to perform as generating a section or a $3 \mathrm{D}$ view from the virtual building model. To enable this real-time model energy analysis, the volume of input data has been reduced to a minimum: as a result, Software's is not designed to produce accredited energy analysis output suitable for official documentation according to local codes and code ratings. If applied in a professional manner, however, Software's are capable of producing results matching the accuracy of high-end energy calculation software. These techniques enable users to get the most out of the calculations.

Using much software, architects can easily analyze their design, at an early stage, for energy efficiency. Providing invaluable feedback on the building's energy performance means the architect can make better decisions on how to conform to regulations and satisfy the interests of the client and the operator of the building. Many design software's have energy evaluation tool for architects application - which aims to provide information about a building's energy performance at the early design phases giving fast feedback for architects on the energy efficiency and sustainability of certain design alternatives. Architects can get results about the energy consumption, carbon footprint and the monthly energy balance easy. Data input: specifying physical properties of the already modeled building envelope using the default values set for different type of building parts or entering custom data, setting up location, weather data, building type and HVAC systems for the project. Evaluation: software passes the data to calculation engine, which performs a dynamic analysis.

Results: report sheets shows the results of the evaluation of the building shell, the energy consumption and cost values, the carbon footprint and the monthly energy balance. Applications perform a screening Life Cycle Analysis (LCA) in the early stages of product design. This allows a Product Engineer or Designer to quickly understand the environmental impact of the product they are designing. As an assembly or part is being designed, the designer can check the environmental impact of different design variations, decisions and scenarios. The design variations could include choice of material, manufacturing process or even the impact of buying parts and transporting it from different sources/locations.

Applications use well known impact assessment methods, indicators and life cycle inventory data that are recognized all round the world. Reduction in energy demand may be achieved by both changes at system level and component level. Components like energy efficient windows and insulation will reduce the energy demand to some degree, while system changes by applying passive house principles will give significantly better improvement. However, changes at system level are perceived as more fundamental and are more difficult to implement according to Unruh (2002) [3]This is in line with the empirical findings as there has not been a conversion from electrical heating to thermal energy and only a few passive houses have been constructed from 2000-2006.

For the fulfillment of institutional and legislation framework for Energy Efficiency, Kosovo can use regional states experiences as adjusted model. Success implementation of Energy Efficiency produce the necessity for application of reforms on local authorities in energy policy, effective policy instrument, local capacity building municipal energy planning.

Realization and demonstration of projects in municipalities, is necessary to advance implementation of Energy Efficiency issues. Demonstration for mobilizing political and networking on the international level-Southeast European Cooperation is one of the important factors for success ful implementation of Energy Efficiency. Development and application of different programs is necessary for successful implementation of Energy Efficiency.

\subsection{Values and Preferences among Building Companies and Consumers}

The previous section discussed how evaluation and motivations for energy policy have changed over the years among designers. However, it is also important to explore preferences and perceptions among the building companies and the consumers. Building companies have traditionally shown very little concern about the energy efficiency of buildings. It is mostly the big building companies that have started to focus on energy and climate, while the smaller ones are still mainly occupied with price 
considerations. According to several interviewees, the demand for new buildings is high and this leads to less attention to energy performance from the building companies -the buildings will be sold anyway. Some technologies have gained less support than others among building companies. 'Here is skepticism towards passive houses, totally. They don't believe in it, but think that people get s ick.'(Interview) However, several elements in passive houses, like thicker insulation and energy efficient windows, are perceived as positive. There are no housing companies that are going to renovate everything to passive house standard; they obviously have energy as a very important focus but no pressure to start. It is their duty and obligation to contribute in this way. Others say that if it gets cheaper they can do it, but take no initiative on their own. (Interview) The time perspective is important for carrying out measures that will improve the energy performance of buildings, as investments may have a long payback time. This is a problem, since building companies operate with a very short time-perspective (interview). However, the building companies want a common standard and method for calculating the lifetime costs of a building. Today everybody does their own calculations and it is difficult to compare. The timeperspective is also important for tenants and the possibilities for implementing measu res to improve energy performance in rented dwellings. Many of Kosovo's residential buildings are rented dwellings (interview). A long time-perspective is necessary for undertaking measures to improve energy performance, but it is a challenge to cover the costs without raising the rent too much. And, as one interviewee pointed out, how shall the tenants take long-term responsibility for improving the energy performance of buildings while they have three months' notice?

The demanders, like the municipalities and private companies, have to require buildings with better energy performance (interview). This is not the case today. Especially for non-residential buildings, energy is not considered important at all. Energy has been too cheap, and other issues have been seen as more important, according to several of the interviewees. An important challenge is thus to increase the demand for buildings with good energy performance. Today this is not an important issue when buying and renting buildings, it was stressed.

\subsection{Building regulations}

Technical regulation No.03/2009 for Thermal Energy Saving and Thermal Protection may be an effective policy instrument for reducing energy demand. There are several steps necessary to implement these regulations. Decision to start developing new minimum energy performance requirements, and necessary resources and funds for its development allocated or secured. Setting of minimum energy performance requirements are incorporated with current Technical regulation on thermal energy savings and thermal protection in building No.03/2009. These regulations are main instrument until Building code comes in place:

- Selection and description of approach to be used for setting of minimum energy performance parameters.

- Derivation of cost - optimal level of energy performance.

- Updating/development of the regulation describing the minimum energy performance requirements.

- Information and training of key stakeholders in the construction industry.

- Updating and development of routines and specifications for documentation and checking of the energy performance requirements.

- Training of national and regional "building inspectorates"

\subsection{Taxes and support arrangements}

Economic measures have traditionally been the most important policy instrument in developed countries that is necessary to implement in Kosovo. While building regulations are mainly for new buildings, taxes and support arrangements are directed especially towards the existing building $\mathrm{s}$ tock. Economic measures that are important in connection with the energy performance of buildings include support for specific technologies, and taxes on energy and $\mathrm{CO}^{2}$ emissions. Such taxes affect the prices of energy 
carriers and aim at providing the consumer with incentives for reducing the use of fossil fuels and electrical heating.

There have been several support arrangements for improving the energy performance of buildings during the period. Most of these have been for measures to be employed in exis ting buildings, except for the support to energy-efficient windows and thermo insulations in new buildings. Other important arrangements include support for installing solar collectors. Some of these arrangements have existed for some time, while others were introduced toward the end of the period under study.

The cultural framework has developed and changed, shaping norms and values. The oil crises, nuclear programs and climate warming have provided important motivations and objectives for policies over the years. These issues are also relevant for understanding the values and preferences among building companies and consumers, and how the various technologies are perceived.

The policy goals have shown ambitious intentions for improving the energy performance of buildings, but no specific targets for conversion from electrical heating to thermal energy. Building regulations are very important instrument for regulating the energy demand of buildings. Despite the widespread belief that building regulations apply to new buildings only, the empirical mapping has revealed that there is a law stating that there also exist requirements for alterations in buildings. Taxes have been an important instrument in modifying the prices of energy carriers, giving incentives to the use of renewable energy sources. We have also noted that Kosovo has a range of support arrangements available for improving the energy performance of buildings. It is widely believed that building regulations apply only to new buildings (interviews). However, there are also requirements for existing buildings, but, according to one interviewee, the law is not followed when doing renovations. The reas on is twofold: the law is unclear, and the municipalities do not follow it up. The requirements for energy efficiency can be imposed only on measures that lead to changes in the building, but the current regulations do not specify or define what is considered as a 'change' in a buildings. The possibility for imposing requirements on the existing building stock is available, but it is not practiced. Measures to reduce energy demand in the existing building stock are of great importance; as such structures will constitute the majority Kosovo's building stock well into the future. The need for more accurate definitions is also recognized in the government that is currently working on new building code. Building regulations may have varying formulations for measuring the energy demand of a building.

\section{Conclusions}

Energy demand models are analytic tools in which mathematical equations are used to estimate how demand might respond to various materials and policy choices. Such models can address a wide range of policy questions and reveal unanticipated effects of policies on other parts of the energy or economic system. When correctly formulated, models can provide necessary checks of consistency with physical and economic constraints that might otherwise be overlooked in policy analysis. But, along with their well-known strengths, social-system models in general have many limitations, as do most traditional energy policy models.

Energy efficiency requirements (Creating a Building Model for Energy Evaluation) in building Code A regulation for energy efficiency in buildings in developing countries, and especially in rapidly developing countries such as Kosovo, seeks to improve comfort and to reduce the dramatic increase in energy consumption. Insufficient efficiency awareness among consumers, designers and banks

The role of politics, economics and social change upon energy efficiency issues is essential and must be integrated into any sustainable approach to a solution. Examining issues such as energy efficiency results in: most decision makers that take decisions, which can influence the energy efficiency of new buildings such as designers, financers, builders, installers and buyers know very little about energy efficiency of buildings. Lack of knowledge in just one of these chains can block the process of increasing energy efficiency in new buildings in Kosovo.

The need for Energy efficiency of buildings in Kosovo

It is important for Kosovo to start the process of developing its adaptation capacity to implement best approaches in energy efficiency of buildings. This process play a key role in enabling Kosovo to se ize this opportunity, and to build a future housing stock which both meets needs and does not harm the 
environment. Achieving, assessing the sustainability rating system is another specific objective of this project.

Challenges that will be assessed include: building sector and responsibility for contribution to environmental problems, importance of maintenance to keep buildings from falling down, approach to environmental sustainability, indicator for environmental sustainability, goal and scope of the asses sment, definition of the subject of assessment, presentation of the results.

\section{References:}

1 Akerlof, George A. 1970 “The Market for 'Lemons': Quality Uncertainty and the Market Mechanism." Quarterly Journal of Economics 84(3): 488-500.

2 Davis, Lucas W. 2010. "Evaluating the Slow Adoption of Energy Efficient Investments: Are Renters Less Likely to Have Energy Efficient Appliances?" Energy Institute at Haas Working Paper 205, June

3 Unruh, Gregory C. 2002. Escaping carbon lock-in. Energy Policy 30 (4):317-325

4 Scott, Richard W. 2001. Institutions and organizations Thousand Oaks, CA: Sage

5 Yin, Robert K. 2003.Case study research. Thousand Oaks, CA: Sage

6 Internet resource

7 Kosovo Energy Efficiency Agency, http://www.wbif.eu/uploads/attached_document/document/996333191/NEEAP_update_KEEA.P $\mathrm{DF}$

$8 \quad$ [Accessed 7.09.2013] 